\title{
Variation in Nucleolar Number among Varieties of Cultivated Rice
}

\author{
Hiko-lchi Oka and Chen-Hui Kao \\ National Institute of Genetics, Misima, Japan
}

Received October 8,1955

The rice plant (Oryza sativa, L.), though generally considered as one species, includes a great many cultivated varieties as well as wild forms, and exhibits a conspicuous varietal variation. Cultivated varieties were classified into two sub-species, "Indica" and "Japonica" by Kato (1928). Terao and Mizushima (1939), however, pointed out from their studies on intervarietal hybrid sterility that the Indica and Japonica types might merely be extreme types of a continuous variation. Later several studies on how to classify rice varieties have been conducted successively. Matsuo (1952) demonstrated that rice varieties could be classified into $\mathrm{A}, \mathrm{B}$ and $\mathrm{C}$ ecotypes. By estimating the tendency of various characters to associate, the present writer (Oka $1953 \mathrm{c}$ ) proposed to divide rice varieties into the "Continental" and "Insular" groups, largely corresponding to the Indica and Japonica types respectively, and to sub-divide the latter group into the "Tropical-Insular" and "Temperate-Insular" groups. Distant varieties of rice thus differ markedly from one another in genetical constitution.

From the view point of cytology, however, every variety of rice has $2 n$ $=24$ chromosomes except for a few spontaneous aberrations such as tetraploids and haploids. It has been demonstrated that the hybrid sterility between varieties is genic (due to duplicate genes maintaining the development of gametes or Gametic-Development genes; Oka $1953 \mathrm{a}, \mathrm{b}$ ), and that tetraploid hybrids between distant varieties show no selective pairing of chromosomes derived from the same parent (Oka 1955). The difference in nucleolus-forming chromosomes may then be the only chromosomal difference that has so far been known among the varieties of cultivated rice.

Selim (1930) was the first to work with intervarietal differences in the number of nucleoli. He reported that in meiotic prophase one nucleolus per nucleus occurs in Japonica type and two in Indica type, but their number in the root tip cells was two in both types. However, Parthasarathy (1938) recognized that both the Japonica and Indica types had four nucleoli in the root tip cells.

Sakai (1938) observed the behavior of nucleolar chromosomes in several varieties of rice, and divided the varieties into "bi-nucleolar" and "quadrinucleolar" types. He thought that Japonica type might belong to the former

1 Contribution from the National Institute of Genetics, Japan, No. 132. 
and Indica type to the latter. The present senior writer (Oka 1944) has also dealt with this problem, and reported that the number of nucleoli in somatic telophasic cell was two in some varieties, while it ranged from two to four in others. In these investigations, however, only a limited number of varieties have been used, so the patterns of variation in nucleolar number are not yet fully understood.

For a better understanding of this problem, the writers observed a number of varieties from various Asian countries, and investigated the variation in relation to the phylogenetic variety groups. The variation seemed to be continuous in nature, and to differ in mode between the variety groups.

\section{Materials and methods}

About one hundred varieties of rice, the same as those used by the senior writer in other papers (Oka 1953, 1954, etc.), were used. Seeds of these varieties were germinated at $30^{\circ} \mathrm{C}$ in petri-dishes, on moistened blotting-paper. Root tips were fixed with Bouin's solution, cut at 10 micra, and stained by Heidenhain's haematoxylin method. In each variety, one to two hundred telophasic nuclei were observed under microscope at the magnification of 2,000 .

\section{Results of observations}

Resting as well as prophasic nuclei usually show one nucleolus, while two to four nucleoli are seen at telophase. It is generally found that newly formed nucleoli at early telophase are roundish in shape, and as the nucleus proceeds into the resting stage, they increase considerably in size. Some elliptic or irregular shaped nucleoli are seen at late telophase, possibly as the result of fusion of two or more nucleoli. In the present investigation, for the purpose of measuring the number of newly formed nucleoli, observations were only recorded relevant to nuclei containing small nucleoli, round in shape.

Thus, variation in the number of newly formed nucleoli was measured in each variety. Some varieties appeared to have two nucleoli, while other varieties showed a variation in number ranging from two to four among the cells of the same root tip. When two nucleoli appeared, they were nearly equal in size. In the case of three, one nucleolus was often smaller than the other two. In the case of four, two of them tended to be larger than the other two. The frequency distribution of varieties with respect to the mean number of newly formed nucleoli is given in Table 1.

As shown in Table 1 , the mean number of nucleoli ranged from 2.0 to 3.6 among the varieties used. Varieties of the Temperate-Insular group had mostly 2.0 as mean number, while the Continental and Tropical-Insular groups showed a wider range of the variation. Assuming a variety with the mean number of 2.0 as the "binucleolar type", and a variety with a value higher than 2.2 as the "quadri-nucleolar type", it may be said that about two thirds 
of the Continental varieties and a half of the Tropical-Insular ones are the "quadri-nucleolar type".

Table 1. Intervarietal variation in nucleolar number in Continental, Temperate-Insular and Tropical-Insular variety groups

\begin{tabular}{lrrrrrrrrrrr}
\hline & \multicolumn{1}{c}{ Mean number of nucleoli } & \multicolumn{3}{c}{ Num. of } \\
Variety Group & 2.0 & 2.2 & 2.4 & 2.6 & 2.8 & 3.0 & 3.2 & 3.4 & 3.6 & var. s \\
\hline $\begin{array}{l}\text { Continental } \\
\text { Insular, }\end{array}$ & 22 & 7 & 11 & 8 & 2 & 3 & 3 & 1 & 1 & 58 \\
$\quad$ Tropical & 15 & 2 & 5 & 1 & 3 & 1 & 2 & & & 29 \\
$\quad$ Temperate & 12 & 1 & 2 & 1 & & & & & 16 \\
\hline Total & 49 & 10 & 18 & 10 & 5 & 4 & 5 & 1 & 1 & 103 \\
\hline
\end{tabular}

The materials used in this research were formerly used for analysing the interrelation in hybrid sterility (Oka 1954). Each of the varieties was crossed with a set of seven others chosen as analyzers in order to find the "reaction type" or the pattern of the analyzers fertile or sterile in the hybrid to the given one. The varieties were thus found to be classified into two groups, I and II, corresponding to the Continental and Insular variety groups, respectively. They were sub-divided further into minor groups, among which Group II $\mathrm{a}$ and $\mathrm{II} \mathrm{b}$ were comparable with the Tropical-Insular and Temperate-Insular groups, respectively. Table 2 shows the range of nucleolar number in these reaction type groups. All of these variety groups except Group II b showed in similar way a wide range of variation in the number of nucleoli. This feature is the same as found in Table 1, since Group II b consists of the varieties of the Temperate-Insular group. It may indicate further that the nucleolar number and the reaction type in hybrid sterility are not significantly related.

Table 2. Variation in nucleolar number in different reaction type groups for hybrid sterility (cf. Oka 1954)

\begin{tabular}{crrrrrrrrrr}
\hline $\begin{array}{c}\text { Reaction } \\
\text { type group }\end{array}$ & 2.0 & 2.2 & 2.4 & 2.6 & 2.8 & 3.0 & 3.2 & 3.4 & 3.6 & $\begin{array}{c}\text { Num. of } \\
\text { var. s }\end{array}$ \\
\hline I a & 2 & & & 2 & & & 2 & 1 & 7 \\
I b & 21 & 7 & 10 & 6 & 2 & 2 & & & 1 & 49 \\
II a & 8 & 2 & 1 & 1 & 1 & 1 & & & 14 \\
II ab & 3 & & 2 & & 1 & & 1 & & 7 \\
II b & 8 & 1 & 2 & & & & & &
\end{tabular}

The geographical variation in nucleolar number is given in Table 3 . As shown in Table 3, most varieties of Indonesia, Celebes, the mountain region of Formosa, and all Japanese lowland varieties, were of the "bi-nucleolar" type, and the "quadri-nucleolar" type was represented by relatively numerous varieties among those of Indo-China, India and Philippines. 
Table 3. Geographical variation in nucleolar number

\begin{tabular}{|c|c|c|c|c|c|c|c|c|c|c|}
\hline \multirow{2}{*}{ Regions } & \multicolumn{9}{|c|}{ Mean number of nucleoli } & \multirow{2}{*}{$\begin{array}{c}\text { Num. of } \\
\text { var. s }\end{array}$} \\
\hline & 2.0 & 2.2 & 2.4 & 2.6 & 2.8 & 3.0 & 3.2 & 3.4 & 3.6 & \\
\hline Indo-China & 4 & & 4 & 2 & 2 & 2 & & & 1 & 15 \\
\hline India and Siam & 4 & 2 & 2 & 1 & & & 3 & 1 & & 11 \\
\hline Philippines & & 2 & 2 & 1 & 3 & 2 & 1 & & & 11 \\
\hline Formosa (plain part) & 7 & 4 & 2 & 3 & & & & & & 16 \\
\hline China Continent & 9 & 1 & 4 & 2 & & & & & & 16 \\
\hline Celebes & 4 & 1 & 1 & & & & 1 & & & 7 \\
\hline Indonesia & 4 & 1 & 1 & & & & & & & 6 \\
\hline Formosa (mountain pt.) & 4 & & 1 & & & & & & & 5 \\
\hline Japan, & & & & & & & & & & \\
\hline lowland varieties & 10 & & & & & & & & & 10 \\
\hline upland varieties & 3 & 1 & 1 & 1 & & & & & & 6 \\
\hline
\end{tabular}

\section{Discussion}

Heitz (1931) has pointed out that the nucleolus is produced at telophase by a definite region of the SAT-chromosomes, viz., the satellite thread or secondary constriction, so that the number, position and size of nuceloli in telophasic nuclei depend upon the number, position and differential activity of those regions. This theory is now generally being accepted by many workers. Matsuura (1938) has reported, however, that in Trillium kamtschaticum whose chromosomes have no satellite, the nucleolus-forming-power is at the distal end of the chromosomes and differs in relative intensity according to the chromosome; the balance of power among the chromosomes may then determine the mode of variation in nucleolar number.

According to Nandi (1936), two pairs of SAT-chromosomes occur in rice. However, since the observation on detailed structure of chromosomes is so difficult in this plant, his conclusion may not be reliable. Judging from the number of nucleoli, rice seems to have one or two pairs of nucleolar chromosomes. In the case of four nucleoli being formed, two of them are often larger than the other two. This may suggest that one pair of the nucleolar chromosomes (the first pair) is superior in activity to the other (the second pair). According to Matsuura's hypothesis, it may be inferred that these two pairs of nucleolar chromosomes may compete with each other to give rise to a variation among cells in nucleolar number. Thus, the intervarietal variation in mean number, rather continuous in appearance, may be understood under the assumption that the nucleolus-forming-power of the second nucleolar chromosome in relation to the first, differs according to genotype. The mean number of nucleoli may then be regarded as indicating the relative activity of the second nucleolar chromosome. Along this line of consideration, it may be inferred further that, if the nucleolus-forming-power of the second nucleolar chromosome is lower than a certain value, two nucleoli are always 
formed, and a "bi-nucleolar type" is brought about. Thus, the variation in nucleolus-forming-power may be considered to be continuous among varieties in the same manner as in other physiological characters.

As mentioned in the introduction, some workers considered that the "Indica" and "Japonica" varieties might have four and two pairs of nucleolar chromosomes respectively. But it is in itself diffcult to divide the varieties of rice into such two groups with a sharp boundary. The present study showed a certain relationship between the phylogenetic variety groups and the mode of variation in nucleolar number. It is possible that a definite tendency to association exists between the combination of genes for various characteristics and the activity of nucleolar chromosomes, but the pattern of differentiation may be a continuous array of intermediate grades between the extreme types.

\section{Summary}

1. The number of nucleoli newly formed in somatic telophasic nuclei was observed in a number of rice varieties from various Asian countries.

2. In some varieties, the number of nucleoli varied from two to four from cell to cell, while in other varieties two nucleoli were found in all cells. The former and the latter varieties may correspond to the so-called "quadrinucleolar" and "bi-nucleolar" types.

3. About two thirds of the "Continental" varieties and a half of the "Tropical-Insular" varieties were of quadri-nucleolar type. In the former, the mean number of nucleoli ranged from 2.2 to 3.6.

4. All Japanese lowland Varieties were of bi-nucleolar type, while both bi- and quadri-nucleolar types were found in different proportions in other regions.

5. It was mentioned that rice might have two pairs of nucleolar chromosomes, and the nucleolus-forming power of the second pair being relative to the first, as shown by the mean number of nucleoli, might vary continuously among varieties.

\section{Literature cited}

Heitz, E. 1931. Des Ursache der gesetzmässigen Zahl, Lage, Form und Grösse pflanzlicher Nukleolen. Planta 12: 775-844.

Kato, S., Kosaka, H. and Hara, S. 1928, On the affinity of rice varieties as shown by fertility of hybrid plants. Rep. Bul. Sci. Fak. Terkult., Kyushu Imp. Univ., Japan 3.

Matsuo, T. 1952. Genecological studies on cultivated rice. Bull. National Inst. Agr. Sci., Japan D 3.

Matsuura, H. 1938. Chromosomes studies on Trillium kamtschaticum, Pall. VI. On the nucleolus-chromosome relationship. Cytologia 9: 55-77.

Nandi, H. K. 1936. The chromosome morphology, secondary association, and origin of cultivated rice. Jour. Genetics 33: 315-336.

Oka, H. I. 1944. On the variation of nucleolar number among varieties of the rice plant. Jour. Soc. Trop. Agr. (Taihoku Imp. Univ,), 16 (2): 79-90. 
Oka, H. I. 1953 a. The mechanism of sterility in the intervarietal hybrid in rice. Jap. Jour. Breeding $2(4): 217-224$.

- $1953 \mathrm{~b}$. Gene analysis of intervarietal hybrid sterility and certation due to certain combinations of Gametic-Development genes. Ibid. 3 (1): 23-30.

- $1953 \mathrm{c}$. Variation of various characters and character combinations among rice varieties. Ibid. $3(2): 33-43$.

- 1954. Classification of rice varieties by intervarietal hybrid sterility. Ibid. $3(3,4)$ : $1-6$.

- 1955. Studies on tetraploid rice. VI. Fertility variation and segregation ratios for several characters in tetraploid hybrids of rice. Cytologia 20 (3): 258-266.

Sakai, K. I. 1938. Nucleoli and nucleolar chromosomes in rice. Commemoration papers on agronomy in honour of Prof. M. Akemine. Tokyo.

Selim, A. G. 1930. A cytological study of Oryza sativa, L. Cytologia, 2: 1-26.

Terao, H. and Mizushima, U. 1939. Some considerations on the classification of Oryza sativa, L. Jap. Jour. Botany 10: 213-258. 